\title{
Kyumin Kim* \\ Oblique nominals, a verbal affix and late merge
}

https://doi.org/10.1515/ling-2020-0179

Abstract: The goal of this paper is to address the syntax of certain oblique nominals in Blackfoot (Algonquian) that are introduced by a set of verbal prefixes called linkers. In the literature, an oblique nominal introduced by a verbal affix always shows certain properties of objects, e.g., agreement. This type of affix is analyzed as forming a complex verb with the main verb via head movement, and the oblique nominal is treated as an object of the complex verb. However, this paper demonstrates that oblique nominals introduced by linkers in Blackfoot do not show certain object properties even though the linker looks like it forms a complex verb. Building on the lack of object properties, linker phrases are proposed to be adjuncts. As proposed for adjuncts generally (e.g., Stephanov, Arthur. 2001. Late adjunction and minimalist phrase structure. Syntax 4(2). 94-125), this paper proposes a late merge analysis for linker phrases. Within an Agree-based model (Chomsky, Noam. 2000. Minimalist inquiries: The framework. In Roger Martin, David Michaels \& Juan Uriagereka (eds.), Step by step: Essays on minimalist syntax in honor of Howard Lasnik, 89-155. Cambridge, MA: The MIT Press, 2001. Derivation by phase. In Michael Kenstowicz (ed.), Ken Hale: A life in language, 152. Cambridge: The MIT Press) where the derivation proceeds by phases (Chomsky 2008), a linker phrase, as an adjunct, lacks the relevant features to participate in the derivation via Agree, and thus it merges late at the end of a given phasal derivation such as $v \mathrm{P}$. When spell out applies, the linker linearizes with a [V-v] complex in the base position, i.e., $v \mathrm{P}$, giving its surface appearance as a verbal affix. Under this view, a linker does not lead to formation of a complex verb as it does not undergo head movement to the verb, unlike applicative affixes, consistent with the absence of object properties.

Keywords: oblique, linker, late merge, verbal affix, applicative

\footnotetext{
*Corresponding author: Kyumin Kim, Department of English Language and Literature, Cheonju University, 298 Daeseong-ro, Sangdang-gu, Cheongju-si, Chungcheongbuk-do, South Korea, E-mail: kyumin.kim2012@gmail.com
} 


\section{Introduction}

In the area of verbal argument structure, one issue of much debate in the literature has been the question of how to project an additional nominal in syntax, which does not belong to the basic argument structure of the verb (in contrast to e.g., an object) (e.g., Alsina and Mchombo 1990; Baker 1988, 1996; Cuervo 2003; Kim 2012; Marantz 1993; Pylkkänen 2008 among others). The additional nominals under question in this paper are those that are not subcategorized by the verb, as illustrated in Chichewa (Bantu) (1):
a. fisi
a-na-dul-a
chingwe ndi
hyen
SP-PAST-cut-A
rope
with knife
'The hyena cut the rope with a knife.'
b. fisi
a-na-dul-ir-a
mpeni
chingwe
hyena SP-PAST-cut-APPL-ASP knife rope
'The hyena cut the rope with a knife.'
(Baker 1985:355-356) ${ }^{1}$

In both clauses in (1), the nominal chingwe 'rope' is a theme that is subcategorized by the transitive verb 'cut'. However, the nominal mpeni 'knife' in (1) is additional in the sense that it is not subcategorized by the transitive verb 'cut'. The non-subcategorized nominals in (1a) and (1b) have more or less the same semantic role, e.g., instrument, often referred to as an oblique, which also includes roles such as benefactive. In particular, it is understood that an instrument role such as the one in (1a) is thematically related to the independent morpheme, $\mathrm{P}$, ndi 'with', while the one in (1b) is thematically related to the suffix -ir on the verb (e.g., Baker 1985; Marantz 1982). I call the latter type of affix an applicative affix following the tradition in Bantu literature. Despite sharing the same oblique role, however, it is well known that these nominals show different syntactic properties. Unlike an oblique DP introduced by an independent $\mathrm{P}$ as in (1a), for instance, the instrument DP introduced by an applicative suffix as in (1b) exhibits a range of object properties such as agreement and A-movement (e.g., Baker 1985, 1988, 1996; for similar properties of oblique nominals, see Bresnan and Moshi 1993; Marantz 1982, 1984, 1993). In particular, Marantz (1982) observes that an oblique DP always shows properties similar to a direct object when it is thematically related to a verbal affix such as the applicative affix in (1b). ${ }^{2}$ This type of

\footnotetext{
1 In this paper, glosses in data from Baker (1985) are adjusted in accordance with the rest of this paper. 2 Peterson (2007) discusses a range of properties shown by applied nominals across languages in comparison to theme nominals. Regarding the object properties of applied nominals and the affixal status of applicative morphemes, which are the central issues of this paper, the data in Peterson (2007) patterns similarly to that discussed in this paper.
} 
applicative affix has been analyzed as forming a complex verb with the verb via head movement resulting in incorporation in the sense of Baker (1985) (to be further detailed in Section 3). Building on the observed syntactic differences, the previous literature identified the grammatical functions of oblique nominals such as in (1) as follows: a (primary) object (1b), and an adjunct (1a). Those identified as primary objects are always introduced by a verbal affix that forms a complex verb, while those identified as adjuncts are introduced by an independent morpheme that does not form a complex verb.

This paper examines oblique nominals that are introduced by a set of verbal prefixes in Blackfoot (Algonquian), which are recognized as Ps in the language (Bliss et al. 2020; Frantz 2009; Kim 2014, 2017a). An example of this type of a nominal is illustrated in (2). ${ }^{3}$ In (2), an oblique nominal annistsi apssi-istsi 'the arrows' is introduced by an instrument prefix oht-. This type of verbal prefix is called a linker in the Blackfoot tradition, as they 'link' their oblique nominal to the events described by the verb phrase (Frantz 2009; Frantz and Russell 1995).,

$\begin{array}{lllll}\text { nitohtsissino'toawa annna saahkomaapi annistsi apssistsi. } & \\ \text { nit-oht-yissino'to- } a \text {-wa } & \text { anna } & \text { saahkomaapi } & \text { ann-istsi } & \text { apssi-istsi } \\ \text { 1-INST-catch.TA-DIR-3S } & \text { DEM } & \text { boy.AN } & \text { DEM-PL } & \text { arrow.INA-PL }\end{array}$

'I caught the boy by means of the arrows.'

3 Throughout this paper, Blackfoot examples (only those that are grammatical) are presented with an additional first line which indicates the orthographic spelling following Frantz (2009) without pitch accent; however, I follow my consultants' orthographic spelling when there is an inconsistency. Unless otherwise noted, all data presented in this paper is from the author's fieldwork. The data presented come from the Kainaa (Blood) dialect. Morpheme breakdowns in this paper are not exhaustive and morphemes irrelevant to this paper are not indicated. The following abbreviations are used in the paper: 1/2/3 - 1st/2nd/3rd person; 21- inclusive 'we'; AI - intransitive animate; AN - animate; APPL - applicative; ASSOC- associative; ASP- mood morpheme; BENbenefactive; CN - conjunct nominalization; DEM - demonstrative; DIR - direct object theme; DUR - durative; FUT - future; II - intransitive inanimate; INA - inanimate; INCP- inceptive; INST instrument; INV - inverse theme; LOC - locative; NOM-nominalization; OP- object prefix; ORDER-order suffix; PL - plural; PAST - past; PRES - present; PRO-enclitic pronouns; S - singular; SP- subject prefix; TA - transitive animate; TI - transitive inanimate.

4 The name 'linker' does not have any particular theoretical status; it is not the same as the 'linker' discussed by Baker and Collins (2006). The linkers in their study show agreement, unlike the linkers in Blackfoot (see Section 4). Also, a linker in Blackfoot is not the same as a 'linker' in den Dikken's (2006) sense, used for something which does not have a particular semantics and plays a role as a predicator. As will be shown in this paper, different Blackfoot linkers have different meanings, and unlike predicators they introduce oblique nominals.

5 In other Algonquian languages, similar adpositional prefixes are called relative roots, and Algonquian linker-type morphemes historically derive from prepositions (e.g., Rhodes 2010). 
The example in (2) shows an oblique nominal being introduced by a verbal affix, i.e., a linker P, similar to applied objects in other languages such as in (1b). Questions arise: do oblique nominals introduced by linkers show the same kinds of object properties as applied objects, and thus can the linker be analyzed as forming a complex verb with the verb via head movement?

This paper provides evidence that obliques introduced by a linker $\mathrm{P}$ do not show language-specific object properties unlike applied objects such as in (1b), and the linker $\mathrm{P}$ is analyzed as a part of an adjunct PP, not as a part of a complex verb. In particular, this paper compares the properties of oblique nominals introduced by a linker $\mathrm{P}$ with those of applied objects in the language, such as beneficiaries, that are also introduced by verbal affixes. The comparison demonstrates that oblique nominals introduced by a linker $\mathrm{P}$ do not show any object properties exhibited by applied objects in the language.

Building on their lack of object properties, I propose that the linker and its nominal in Blackfoot such as in (2) form an adjunct PP. Assuming as in previous studies that adjuncts are added to a derivation late (e.g., Lebeaux 1988; Stepanov 2001), I propose a late merge account of linker PPs in the framework of Agree-based derivation (Chomsky 2000, 2001) where derivation proceeds by phases (Chomksy 2008): an adjunct PP projected by a linker P merges late at the end of a given phasal derivation, as it lacks features related to object properties and thus cannot participate in Agree. The specific point where the linker PP late merges is proposed to be a phasal level, i.e., $v \mathrm{P}$, after other cyclic derivations up to $v \mathrm{P}$ are completed. I also propose linearization of the linker $\mathrm{P}$ in situ, namely at $v \mathrm{P}$, without head movement to the verb, building on Julien's (2002) work on affix orders. Thus, a linker P does not form a complex verb unlike an applicative affix such as in (1b), which is consistent with the lack of object properties of oblique nominals introduced by the linker Ps.

The paper is organized as follows: Section 2 provides some background on Blackfoot. Section 3 discusses the main data on oblique nominals in Blackfoot. This section also provides a brief discussion on the previous analyses of applicative affixes as forming a complex verb, which will be shown not to be the case for the linker $\mathrm{P}$ in Blackfoot. Section 4 demonstrates that nominals introduced by linker Ps do not show language-specific object properties and concludes that linker PPs are adjuncts. Section 5 develops a late-merge analysis for adjunct linker PPs, which captures the affixal status of the linker P despite its being an adjunct head. Section 6 shows that a linker must be a $v$ P adjunct, and cannot attach lower than $v \mathrm{P}$, by providing evidence from abstract nominalization and idioms. Section 7 concludes the paper. 


\section{Background on Blackfoot}

In Blackfoot, the person, number, and gender features of at most two participants a subject and an object (of transitives) - are cross-referenced in verbal affixes, and word order is relatively free. Regarding the nominals introduced by linkers discussed in this paper (in Section 3), they freely appear either sentence initially or finally; they can also appear before an object.

Among the verbal affixes, the so-called 'final' morphemes are suffixes which indicate the transitivity of the verb and the grammatical animacy of the grammatical functions, subject (S) or object (O) (Frantz 2009), which more or less correspond to the thematic roles of agent and theme, respectively. Four finals are presented in (3). The names of the finals in (3) follow traditional Algonquianist terminology (e.g., Bloomfield 1946). The forms of the finals vary according to the verb stem that they attach to (see (4)), and often they are not easily separable from a verb stem, differing in a suppletive fashion (e.g., see (4 and 5)).
a. Animate Intransitive (AI): $\mathrm{S}$ is animate
b. Inanimate Intransitive (II): $\mathrm{S}$ is inanimate
c. Transitive Animate (TA): $\mathrm{O}$ is animate
d. Transitive Inanimate (TI): $\mathrm{O}$ is inanimate

In Blackfoot, nouns are categorized into two classes: animate and inanimate. Nouns in the inanimate class are inanimate things. Nouns in the animate class may be humans or animals, but they may also be certain inanimate items. For instance, nouns such as 'wagon', 'knife', and 'blanket' belong to the animate noun class although they are semantically inanimate (Frantz 2009; Frantz and Russell 1995). The verb finals in (3) refer to this grammatical animacy classification, rather than to semantic animacy. For example, in (4a) below, the verb 'see' is in a TA form (cf. ini 'see.TI' in (4c)), indicating that the verb is transitive, and that its object is grammatically animate. Thus, in (4a), this TA verb appears with the subject 'I' and the animate object 'that boy'. However, as shown in (4b), it disallows a grammatically inanimate object such as 'the dress'. A grammatical version of (4b) is shown in (4c): in order to have an inanimate object, the verb 'see' has to be in the TI form, ini, unlike the TA form, ino, in (4a). Both TA and TI verbs require a DP object, and thus an object noun must be preceded by a demonstrative such anna or anni, as indicated in (4a) and (4c).

(4) a. nitsinoawa anna saahkomaapi.

$\begin{array}{lcl}\text { nit-ino-a-wa } & \text { *(anna) } & \text { saahkomaapi } \\ \text { 1-see.TA-DIR-3SG } & \text { DEM } & \text { boy.AN } \\ \text { 'I saw the boy.' } & & \end{array}$




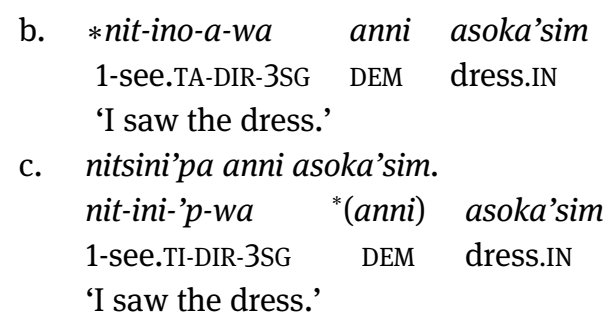

The transitive verbs in (4a) and (4c) have a corresponding intransitive form, namely an AI verb, as illustrated in (5a): the AI verb yaapi 'see' is in a morphologically different form from both the TA and TI forms in (4a) and (4c). ${ }^{6}$ As an AI verb, the verb in (5a) signals that its subject ('I') is animate, and it is intransitive. In Blackfoot, the AI class forms a heterogeneous set consisting of unergatives, unaccusatives, and pseudotransitives (Ritter and Rosen 2010). The first two types are familiar intransitives that are found in other languages (e.g., English), which I will not discuss further. The last type may be a less familiar type of intransitive, and warrants some discussion. Some AI verbs are classified as pseudotransitive in the sense that they cannot have a full-fledged object such as a DP, but they allow a less fully-fledged object such as an optional NP (Ritter and Rosen 2010). As shown in (5a), for example, the AI verb yaapi 'see' can appear without an object, and as shown in (5b) the same verb can also appear with an NP object such as saahkomaapi 'a boy'. Unlike the DP objects of transitive verbs as in (4a) and (4c), the object of an AI pseudotransitive verb cannot be preceded by a demonstrative like anna 'that', as shown in (5b). A pseudotransitive AI verb is also different from its transitive counterpart in that it allows either an animate or inanimate object: the AI verb in (5a) is compatible with either the animate object saahkomaapi 'a boy' as in (5b) or the inanimate object asoka'sim 'a dress' as in (5c).

(5) a. nitsaapi.

nit-yaapi

1-see.AI

'I saw (someone/something).'

b. nitsaapi saahkomaapi.

nit-yaapi $\quad(*$ anna $) \quad$ saahkomaapi

1-see.AI DEM boy.AN

'I saw a boy.'

6 TA/TI-AI alternating verbs such as 'see' in (4a) and (4c) do not have II verb counterparts (Frantz and Russell 1995; Ritter and Rosen 2010). 
c. nitsaapi asoka'sim.

nit-yaapi asoka'sim

1-see.AI dress.IN

'I saw a dress.'

I adopt Ritter and Rosen's (2010) proposal that final suffixes, except II verb finals and unaccusative AI finals, are represented as agentive $v$ s in the sense of Chomsky (1995): they introduce an external argument and license a (primary) object. ${ }^{7}$ An unaccusative AI final is proposed to project a defective $v$ that does not have a specifier position (Ritter and Rosen 2010), which I assume in this paper. When no distinction is needed, I refer both types of $v$ as $v$ in the rest of the paper.

In addition to verb final suffixes, Blackfoot has another set of verbal suffixes called theme markers that indicate the direction of action between two participants of the event denoted by the VP. ${ }^{8}$ The particular direction is indicated by a DIRECT or INVERSE theme marker and the presence of the relevant theme marker is constrained by person hierarchy. In brief, for instance, in (4a), a DIRECT theme marker $-a$ is shown, and glossed as DIR: roughly speaking, the DIRECT theme marker indicates that the direction of action, 'seeing' is from the more highly ranked $1^{\text {st }}$ person 'I' to the less highly ranked 3rd person 'that boy'. As theme markers indicate a relation between two participants, they can be marked on transitives only, such as TA and TI verbs, but not on intransitives.

\section{Oblique nominals in Blackfoot, a complex verb, and an adjunct PP}

This paper mainly discusses oblique nominals introduced by two types of linkers in Blackfoot among those listed in Frantz (2009) and Frantz and Russell (1995): (i) instrument (iiht-/oht-) and (ii) associative (iihp-/ohp-) (Frantz 2009) illustrated in (6). ${ }^{9}$ The first forms appear in a word-initial position, while the second forms appear elsewhere.

(6) a. nitohtsissino'toawa annna saahkomaapi annistsi apssistsi. nit-(oht)-yissino'to-a-wa anna saahkomaapi (ann-istsi apssi-istsi) 1-INST-catch.TA-DIR-3S DEM boy.AN DEM-PL arrow.INA-PL 'I caught the boy by means of the arrows.'

7 II verbs are concluded to belong to the class of unaccusatives (Ritter and Rosen 2010). II verbs are understudied in the Blackfoot literature and it appears that the linkers investigated in this paper cannot appear with II verbs. Thus, I do not mention this class further.

8 More details of theme markers will be discussed in Section 5.3.

9 Frantz (2009) noted third variants, omohp- for the associative linker and omoht- for the instrument linker, but my consultants do not have these variants. 
b. nitohpinisi'yi anna saahkomaapi.

$\begin{array}{ll}\text { nit-(ohp)-inisi'yi (anna } & \text { saahkomaapi) } \\ \text { 1-ASSOC-fall.AI DEM } & \text { boy.AN } \\ \text { 'I fell with the boy.' } & \end{array}$

The instrument linker oht- in (6a) introduces an instrument to the event of "catching the boy'. The associative linker in (6b) introduces an associate 'the boy' to the event of 'falling'; in particular, it introduces an entity which accompanies the theme (Meadows 2010). The associative linker may be interpreted similarly to comitatives found in other languages; it is translated most closely as 'with'.

Instrument and associative PPs are optional, similar to ordinary adjunct PPs, as indicated in (6) above. ${ }^{10}$ However, the nominal introduced by the linker prefixes cannot be omitted, as shown in (7) for the example in (6a).

$$
\begin{aligned}
& \text { *nit-oht-yissino'to- } a-w \quad \text { aanna saahkomaapi } \\
& \text { 1-INST-catch.TA-DIR-3s DEM boy.AN } \\
& \text { Intended meaning: 'I caught the boy by means of something.' }
\end{aligned}
$$

As with other linkers in the language, the linker prefixes under investigation do not have adpositional counterparts in the language (Frantz 2009; Kim 2017b).

In Blackfoot, there is another type of oblique nominal that differs from the type introduced by the linker prefix Ps in that it is introduced by a suffix. An example of this is shown in (8).

$$
\begin{aligned}
& \text { nitsskiitoawaistsi nitana. } \\
& \text { nit-ihkiit-o-aa-wa-aistsi } \quad \text { nitana } \\
& \text { 1-bake-BEN.TA-DIR-3s-3PL.PRO my daughter } \\
& \text { 'I baked them for my daughter.' (Frantz 2009: 102) }
\end{aligned}
$$

In (8), the suffix $-o(\mathrm{mo})$ on the verb root introduces a beneficiary into the event of 'baking them'. Like linkers, the benefactive suffix does not have an adpositional counterpart. However, unlike the oblique nominals of linkers, the beneficiary oblique introduced by suffix $-O(\mathrm{mo})$ as in (8) shows some language-specific object properties (e.g., Frantz 2009) (further detailed in Section 4), similar to applied objects in Bantu languages. Moreover, similar to applied objects in Bantu (e.g., Bresnan and Moshi 1993), beneficiary nominals as in (8) are referred to as primary objects in distinction to theme nominals (which are known as secondary objects) in their object properties (Frantz 2009). I also adopt these terms for referring to beneficiary and theme nominals in this paper.

10 Not all linkers are optional. For instance, a direction linker that introduces a goal phrase has been shown to be obligatory with inherently directed motion verbs, and such a direction linker phrase is proposed to be a PP object of inherently directed motion verbs (Kim 2015a). 
The beneficiary suffix has been treated as a derivational morpheme deriving a TA verb (Frantz 2009), and as such it cannot be omitted in the clause. This property of the beneficiary suffix is well-known to be shared with other derivational morphemes such as the language's causative affix, which introduces a primary object (Frantz 2009). The linkers are different from the benefactive suffix in this respect; for example, as shown in (6b), a linker phrase is optional, the addition of a linker does not change the category of the verb, and the verb remains the same, as an AI verb. Importantly, these differences hint that oblique nominals introduced by linkers cannot be treated in the same way as applied beneficiaries introduced by $-o(m o)$, which will be shown to be the case in Section 4.

As briefly discussed in Section 1, the previous literature treated oblique nominals differently. Those which are introduced by a verbal affix such as an applicative morpheme are identified as objects, as is the case for beneficiaries in Blackfoot, as in (8). For example, for applied objects, the recent studies propose a functional head above VP, namely an applicative (Appl) head (e.g., Marantz 1993; McGinnis 2001; Pylkkänen 2008), ${ }^{11}$ which is also proposed for beneficiary nominals in Blackfoot (Bliss 2010). Under this type of approach, the applicative morpheme is realized as a functional head, Appl, and this head introduces the oblique nominal, as schematically illustrated in (9) for the Blackfoot example in (8). In (9), Appl merges above VP, and introduces the applied object in its specifier. $^{12}$

$$
\begin{aligned}
& {\left[{ }_{v \mathrm{P}}\right. \text { 'I' [v [ApplP }} \text { nitana } \\
& \text { 'my daughter' ihkiit-omo }
\end{aligned}
$$

In (9), $\mathrm{V}$ undergoes head movement to Appl (or vice versa depending on one's analysis), incorporation in the sense of Baker (1985), resulting in a complex verb [V-Appl (ihkiit-omo)]. Thus, the applied object is considered the object of a complex verb [V-Appl]. Importantly, this type of analysis captures the affixal status of the applied morpheme via head movement, and the applied nominal is treated as an object of the complex verb that consists of an applicative affix and the verb.

On the other hand, those that are not introduced by a verbal affix but by an independent $P$ are identified as adjuncts (see the example in (1a)). Oblique nominals introduced by an independent P (1a) have been observed to lack object properties, unlike oblique nominals introduced by an applicative suffix (1b) (e.g.,

11 Not all applicative approaches can account for the object properties of applied nominals (see McGinnis 2001). This paper considers the most typical applicatives as discussed in Section 3.

12 This type of Appl is called high Appl, in contrast to low Appl, which takes a DP complement and merges below VP. As the applied nominals of both types of Appl show the properties of primary objects (e.g., McGinnis 2001), I do not distinguish them. 
Baker 1985, 1988, 1996, 2006; Marantz 1984, 1993; McGinnis 2001; Nakamura 1997). Lacking object properties, this type of PP has been identified as an adjunct serving as a modifier to a VP, and it is proposed to adjoin to the VP (e.g., Baker 1998, 1996, 2006; Marantz 1984). Thus, for this type of $P$, there is neither head movement nor incorporation to $\mathrm{V}$.

Given the fact that linkers are verbal affixes similar to the benefactive affix in the language, we may predict that oblique nominals introduced by linkers are identified as objects, similar to beneficiaries in the language. ${ }^{13}$ In Section 4 which follows, I demonstrate that oblique nominals introduced by a linker do not show language-specific object properties, unlike oblique nominals introduced by the beneficiary affix. ${ }^{14}$ In Section 5, building on the consequences of Section 4, I propose a late merge analysis of linker PPs where the linker P does not form a complex verb.

\section{Syntax of oblique nominals in Blackfoot: Linker PP vs. beneficiary}

This section demonstrates that the nominals introduced by linkers do not show syntactic properties of primary objects, unlike applied nominals, namely beneficiaries, in the language. In the following subsections, I discuss language-specific syntactic properties of primary objects (Frantz 2009): sentience restriction, person prefix marking, theme marking, and suffixal agreement. Note that except the property of the sentience restriction, these properties are also shown by direct objects of mono-transitive verbs in the language, which I do not discuss except where relevant.

13 Although instrument and associative linkers have been generally recognized as adjunct PPs in the language (e.g., Meadows 2010), there has been no thorough syntactic comparison of the linkers to applicative morphemes in Blackfoot or other languages, as carried out in this paper. There are some studies on other types of linkers in the language, namely spatial linkers - for example, Kim (2015a, 2017a) on the aspectual structure of a direction linker (itap-), and Bliss et al.(2020) on the syntax of a locative linker (it-) in comparison to a locative P in Plains Cree (Algonquian).

14 Standard diagnostics such as passivization or reciprocalization employed in the applicative literature (e.g., Baker 1988) cannot be applied in Blackfoot. Passivization is absent in the language; in fact, Algonquian languages including Blackfoot lack A-movement (Ritter and Rosen 2005). The syntax of reciprocalization in the language is understudied, which makes it difficult to use it as a concrete diagnostic for the purpose of this paper. 


\subsection{Sentience restriction}

Sentience refers to real-world or semantic animacy, or the ability to sense or perceive (Speas and Tenny 2003). Note that in Blackfoot sentience is not the same as grammatical animacy: grammatical animacy includes both sentient (e.g., 'boy') and non-sentient (e.g., 'wagon' or 'blanket') entities as discussed in Section 2.

Sentience plays an important role in various parts of Blackfoot grammar. In particular, a sentience restriction in the language has been recognized to be a defining property that distinguishes nominals that carry a grammatical function - subject or primary object - from those which do not, such as adjuncts (e.g., Frantz 2009; Kim 2015a; Ritter and Rosen 2010; Wiltschko and Ritter 2015): subjects and primary objects must be sentient, unlike adjuncts. In recent studies on Blackfoot, the sentience restriction has been proposed to be a part of narrow syntax, represented as syntactic agreement (Kim 2017b; Wiltschko and Ritter 2015). ${ }^{15}$ In light of these studies, the sentience restriction is an important criterion in Blackfoot to determine whether a given oblique nominal is a primary object or an adjunct. The nominals introduced by the benefactive suffix and by linker Ps show a difference in the sentience restriction. Beneficiaries must be sentient (Bliss 2007; Frantz 2009), unlike nominals introduced by a linker P.

First consider the beneficiary nominal illustrated in (10a). As a benefactive suffix, $-o(m o)$ is a type TA final, so the primary object of the derived applicative verb is predicted to be grammatically animate. In accordance with this prediction, in (10a), the beneficiary 'the baby', which is animate, is introduced by the suffix $-o(\mathrm{mo})$. If the beneficiary is grammatically inanimate, as is 'the bed' in (10a), the sentence becomes ungrammatical.

(10) a. nitaahkanomoawa anna issitsimaan amiksi si'kaaniksi.

$\begin{array}{llll}\text { nit-waahkan-omo-a-wa } & \text { [anna issitsimaan]/*[anni } & \text { akssin] } \\ \text { 1-sew-BEN.TA-DIR-3S } & \text { DEM baby } & \text { DEM } & \text { bed.INA } \\ a m-i k s i & \text { si'kaan-iksi } & & \\ \text { DEM-AN.PL } & \text { blanket-AN.PL } & & \end{array}$

'I sewed those blankets for the baby/*the bed.'

(Bliss 2007:07)

15 Although details differ, sentience is represented as a feature such as [m(ental) state] (Kim 2017b; Ritter 2015) or [H(igh animay)] (Wiltschko and Ritter 2015) on a relevant functional head. As such, for instance, it is in an Agree relation with a nominal in the specifier of the relevant functional head (e.g., Kim 2017b; Ritter 2015). 
b. *nit-waahkan-ii-'p-wa nitana/anni asoopa'tsis

1-sew-TI-DIR-3S my daughter/DEM chair.INA

anni-istsi isttsikapoko-istsi

DEM-PL leather.INA-PL

Intended meaning: 'I sewed the leathers for my daughter/the chair.'

c. nitaahkanii'pa anni isttsikapoko.

nit-waahkan-ii-'p-wa anni isttsikapoko/*anna si'kaan

1-sew-TI-DIR-3S DEM leather.INA / DEM blanket.AN

'I sewed the leather $/ *$ the blanket.'

Without the suffix -omo, a beneficiary nominal cannot be introduced, as shown in (10b). The verb root in (10b) is the same as in (10a); however, it is in a TI form with the TI suffix -ii, and lacking -omo. ${ }^{16}$ The fact that it is in a TI form is supported by the data in (10c): the verb only allows an inanimate object noun such as 'the leather', but not an animate object such as 'the blanket'. As a TI verb without the beneficiary suffix -omo, it cannot have a beneficiary nominal, regardless of its animacy status, as shown in (10b): neither animate 'my daughter' nor inanimate 'the chair' is allowed.

Importantly, the range of possible nominals allowed by the suffix is more restricted than would be predicted by its status as a TA verb. The beneficiary introduced by the suffix must be sentient (Bliss 2007; Frantz 2009). That is, nouns which are grammatically animate but semantically inanimate are not allowed as beneficiaries. This is illustrated in (11a) with a newly elicited example.

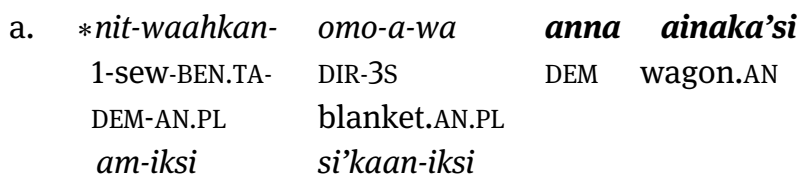

'I sewed those blankets for the wagon.'

16 The benefactive morpheme - $o(\mathrm{mo})$ can be suffixed to either a verb root or a verb stem (e.g., a TA or AI) (Frantz 2009). The examples presented in this section show the morpheme suffixed to a verb root, and the latter type of example is illustrated in (i). In (i), the benefactive suffix -omo affixed to the AI stem verb sstaahkaht 'suckle'.

nitsstaahkahtomooka nitsssitsimaani.
nit-sstaahkaht-omo-ok-wa nitssitsimaanyi
1-suckle.AI-BEN.TA-INV-3S my baby
'She nursed my baby for me.'

(Frantz 2009:103)

I do not question the issue of this variation in the site to which the benefactive morpheme can be affixed. What is relevant to the current discussion is that the benefactive suffix belongs to the set of TA markers (Frantz 2009). 
(In the context where those blankets are supposed to cover the wagon to protect it from the winter cold.)

b. nitsinoawa anna aninaka'si.

nit-ino-a-wa anna ainaka'si

1-see.TA-DIR-3SG DEM wagon.AN

'I saw the wagon.'

c. *nit-ini-'p-wa anna ainaka'si

1-see.TI-DIR-3SG DEM wagon.AN

'I saw the wagon.'

Here, the beneficiary is the grammatically animate noun 'wagon' (11a). Despite its animate classification, it is not sentient; thus, the sentence is ungrammatical. That the noun ainaka'si 'wagon' is a grammatically animate noun is shown by the fact that the noun is allowed as the object of a TA verb (11b), but not of a TI verb (11c).

By contrast, oblique nominals introduced by linkers do not show this type of restriction; linkers allow either sentient or (in)animate nominals. As illustrated in (12) with the instrument linker, either the sentient 'John' or the inanimate 'soup' is allowed. Moreover, a grammatically animate but non-sentient instrument 'the knife' is also allowed.

(12) anna John/anni koopis/anni isttoan nitohtaakomi'taki.
anna John / anni koopis/ anni isttoan nit-oht-waakom-i'taki DEM John.AN/ DEM soup.INA/ DEM knife.AN 1-INST-love-AI
Lit. 'I am in love, by means of John/the soup/the knife.'
('I love John/the soup/the knife.')

The associative linker ohp- shows the same pattern. As shown in (6b) earlier, it can introduce a sentient nominal ('the boy'). As shown in (13), it can also introduce a grammatically animate noun ('vase', 13a) or an inanimate noun ('water', 13b).

(13) a. nitohpohpommatoo'pa anni pisatssaisski mokamiipoohko'siksi. nit-ohp-ohpommatoo-'p-wa anni pisatssaisski mokamiipoohko's-iksi 1-ASSOC-buy.TI-DIR-3S DEM flower.INA vase.AN-PL 'I bought the flower with vases.'17

17 For Examples (13a) and (13b), the best translation is as a comitative as discussed in the text. To be interpreted as conjoined elements, the conjunction $k i$ 'and' appears, rather than the associative prefix. 
b. nitohpohpommatawa anna mamii aohkiistsi. nit-ohp-ohpommat-a-wa anna mamii 1-ASSOC-buy.TA-DIR-3S DEM fish.AN water.INA-PL 'I bought this fish with water.'

\subsection{Person prefix marking}

In Blackfoot, verbs can be marked with affixes that indicate the person value of their primary object (Frantz 2009). In particular, first, second, and third persons are indicated by prefixes (nit-, kit-, ot-, respectively) on verbs. A beneficiary introduced by the suffix $-o(m o)$ can appear as a person prefix as shown in (14a), which suggests that it is a primary object. The person prefix can co-occur with an optional full pronoun such as niisto for added emphasis, as shown in (14a). However, the sentence is ungrammatical if this beneficiary is expressed solely with the pronoun, entirely lacking the person prefix (14b).

a. anna John nitsskiitomooka napayin (niisto).

$\begin{array}{llll}\text { anna John nit-ihkiit-omo-ok-wa napayin } & \text { (niisto) } \\ \text { DEM John 1-bake-BEN.TA-INV-3S } & \text { bread.INA } & \text { I } \\ \text { 'John bakes bread for me.' } & & \end{array}$

b. *anna John ihkiit-omo-ok-a napayin niisto

DEM John bake-BEN.TA-INV-3s bread.INA I

Intended meaning: 'John bakes bread for me.'

In contrast, nominals introduced by linkers cannot be expressed via person prefixes, unlike beneficiaries introduced by the suffix $-o(\mathrm{mo})$. This is illustrated in (15a): when the associative linker introduces the associate 'me', the person prefix nit- as the expression of the associate results in ungrammaticality. (15b) shows the grammatical variant of this sentence, where the associate is expressed via an independent pronoun 'I', niisto. ${ }^{18}$

18 The pronoun can be realized with either a proximate suffix - $w a$ or an obviative suffix -yi: niisto$\boldsymbol{w a}$ or niisto-yi. Descriptively, a proximate nominal is more prominent in the discourse than an obviative nominal, and 3rd person nominals are marked by one of these suffixes (e.g., Frantz 2009). As observed in Frantz (2009), while the presence of a proximate animate 3rd person nominal in the sentence can trigger the -yi suffix on a non-subject 1st or 2nd person independent pronoun, the pronoun does not behave syntactically as a 3rd person. I remain agnostic to the issues relevant to proximate and obviative marking, and indicate the pronoun in its bare form without proximate or obviative marking. Another relevant issue pointed by a reviewer is that a beneficiary cannot be expressed by a person prefix when the subject is in 3rd person proximate and the secondary object is in 3rd person obviative, which I do not discuss. 
(15) a. *anna saahkomaapi nit-ohp-innisi-wa DEM boy 1-ASSOC-fall.AI-3s

'That boy fell with me.'

b. niisto anna saahkomaapi iispinnisi.

$\begin{array}{lll}\text { niisto anna saahkomaapi } & \text { iihp-innisi-wa } \\ \mathrm{I} & \text { that boy } & \text { ASSCO-fall.AI-3S }\end{array}$

'That boy fell with me.'

The contrast shown in this section between the beneficiary morpheme and the linkers indicates that the nominals introduced by linkers cannot be treated in the same way as an applied beneficiary, i.e., a primary object. ${ }^{19}$

\subsection{Theme (DIRECT/INVERSE) marking}

In Blackfoot, like all other Algonquian languages, the direction of the action described by the verb is indicated by theme markers, as was briefly mentioned in Section 2: by either DIRECT or INVERSE morphology (Frantz 2009) (cf. Table 1 below). DIRECT-INVERSE systems make reference to a person scale such as that shown in (16), which is simplified for the purpose of this paper. If the direction of action is from a 1st/2nd person to a 3rd person ( $1>3$ or $2>3$ ) or from a 1st person to a 2 nd person $(1>2)$, the verb is marked as DIRECT. If the direction is the opposite, from a

19 As suggested by a reviewer, the contrast between beneficiaries and nominals introduced by linkers shown in this section may suggest that the two nominals show a contrast with respect to the Person Case Constraint (PCC) (e.g., Adger and Harbor 2007). A descriptive generalization of the PCC is presented in (i).

1. (i) The Person Case Constraint (PCC)

In a ditransitive, where both internal arguments are realized as phonologically weak elements, the direct object must be third person (Adger and Harbor 2007).

In other words, the PCC states that in a ditransitive, a pronominal direct object cannot be a 1st or 2nd person. With nominals introduced by linkers, the PCC may not apply, as they cannot be realized as weak elements such as pronominal prefixes, but have to appear as independent full pronouns, as shown in this section. In contrast, this section has shown that a pronominal beneficiary can appear as a person prefix. Given the Blackfoot-specific facts that only one person prefix per verb is allowed, and in a ditransitive clause only a subject or a primary object such as a beneficiary can appear as a person prefix, a secondary object that appears with a pronominal beneficiary in the same sentence cannot appear as a weak element such as a person prefix. Thus, the PCC may not apply in this case either. 
3rd person to a 1st/2nd person $(3>1$ or $3>2$ ) or from a 2 nd person to a 1 st person $(2>1)$, then the verb is marked as INVERSE. As theme markers encode grammatical relations between two entities in the clause, they appear obligatorily only on transitive verbs such as TA or TI verbs, but they cannot appear on intransitives, i.e., AI or II verbs. Unlike TA verbs, however, only a DIRECT theme marker is allowed with TI verbs, while an INVERSE theme marker is not allowed. ${ }^{20}$

Table 1 below provides a summary of the theme suffixes (in bold) for TA forms for the simplified person scale in (16). The examples in this section are all in TA forms, and thus theme suffixes for the TI paradigm are not presented. In the table, the pronominal prefixes are indicated in brackets: 1st person nit-, 2nd person kit-, and 3rd person ot-. These prefixes are in brackets as they do not appear when the relevant person is not in a pronominal form. Note that in Blackfoot only one person prefix can appear per verb, and the 2nd person prefix always takes precedence over other person prefixes (Frantz 2009), as reflected in Table 1 (see (17a) for a concrete example). ${ }^{21}$ As for the action between 1st person and 3rd person pronominals, it is the 1st person that takes precedence over the 3rd person regardless of the direction of the action; thus, the 3rd person prefix does not appear in any case presented in the table.

$$
\begin{aligned}
& \text { Simplified scale } \\
& \text { 1st }>\text { 2nd }>\text { 3rd }
\end{aligned}
$$

Consider (17a) where the TA verb has the DIRECT theme marker - $a$. This marker appears because the 1st person ('I') acts on a 3rd person ('the boy'). In contrast, in (17b), the second person ('you') acts on the 1st person ('I'); thus, the INVERSE marker -ok appears on the verb. In this particular case, the verb also has the suffix $-i$ which indicates that the object is in 1st person; this is preceded by the INVERSE marker (Frantz 2009).

20 In Blackfoot, with transitives, the subject always initiates the action and has to be sentient (Frantz 2009; Kim 2017a; Ritter and Rosen 2010), as discussed in Section 4.1. Thus, in clauses marked by a TI verb, where one participant is always inanimate, the direction of action cannot be indexed by an INVERSE theme marker. Otherwise, the direction of action would be from an inanimate entity (i.e., a subject) to a sentient entity (i.e., an object), which is ruled out by the sentience restriction.

21 Thus, the 2nd person pronominal form kit- appears when the direction of action is between 1st person and 2nd person pronominals, as shown in (i): the 1st person acts on the 2nd person and in this case, the DIRECT theme suffix is $-o$, which follows the verb.

(i) kitsission'too.

kit-yissino'to-o

you-catch.TA-DIR

'I caught you.'(1 > 2) 
Table 1: Theme (DIRECT/INVERSE) suffixes for TA paradigm. ${ }^{22}$

\begin{tabular}{llll}
\hline $\begin{array}{l}\text { Object } \\
\text { Subject }\end{array}$ & 1 & 2 & 3 \\
\hline $\mathbf{1}$ & & $\begin{array}{c}\text { (kit-)V-o }(1>2) \\
\text { DIRECT }\end{array}$ & (nit-)V-a (1 > 3) DIRECT \\
$\mathbf{2}$ & $\begin{array}{c}\text { (kit-)V-ok-i }(2>1) \\
\text { INVERSE } \\
\text { (nit-)V-ok }(3>1)\end{array}$ & $\begin{array}{c}\text { (kit-)V-a }(2>3) \\
\text { DIRECT }\end{array}$ \\
$\mathbf{3}$ & INVERSE & INVERSE & \\
\hline
\end{tabular}

(17) a. nitsission'toawa anna saahkomaapi. nit-yissino'to-a-wa anna saahokomaapi 1-catch.TA-DIR-3S DEM boy 'I caught the boy.' $(1>3)$

b. kitsission'toki kit-yissino'to-ok-i 2-INST-catch.TA-INV-1

'You caught me.' $(2>1)$

Like the direct object of the verb in a transitive clause as shown in (17), the nominal introduced by the suffix - $o(\mathrm{mo})$ must be indexed by a theme marker as shown in (18). The third person subject 'John' acts on the 1st person beneficiary; consequently, the verb is marked with the INVERSE marker -ok. Without this INVERSE marker, the sentence is ungrammatical.

$$
\begin{array}{lllll}
\text { nitsskiitomooka anni napayin anna John } & & \\
\text { nit-ihkiit-omo-*(ok)-wa } & \text { anni napayin } & \text { anna } & \text { John } \\
\text { 1-bake-BEN.TA-INV-3S } & \text { DEM bread.INA } & \text { DEM } & \text { John } \\
\text { 'John baked the bread for me.'(3>1) } & &
\end{array}
$$

Recall that a verb suffixed with the beneficiary morpheme is a TA verb (Frantz 2009). TA verbs require that their object be grammatically animate; thus, the beneficiary 'me' must be analyzed as the primary object in (18), rather than the inanimate theme 'bread'. Accordingly, the INVERSE marker indicates the direction of action between the subject 'John' and the animate beneficiary, not the inanimate theme.

Unlike the beneficiary in (18), a nominal introduced by a linker cannot be indexed by a theme marker. For example, in (19a), the animate DP anna si'kaan 'the

22 Theme suffixes are morphologically different depending on the type of order, which is not the concern of this paper. All examples in this paper are in independent order (which appears in main clauses), and the theme suffixes in Table 1 show a TA paradigm in independent order. 
blanket' is introduced by the instrument linker oht-, and the direction of the action is from a 2nd person ('you') to a 1st person ('me'). This is indexed with an INVERSE marker -ok, and the sentence is grammatical. In this example, the 2nd person subject appears as a prefix to the verb, and the 1st person object is indicated by the suffix $-i$, similar to the example in (17b). As the instrument 'the blanket' is grammatically animate in the language, it might be considered an object of the TA verb and indexed by the theme marker. ${ }^{23}$ If this were the case, the sentence in (19a) would be marked with a direct theme marker $-a$, and the 3rd person instrument would have to agree with the verb, indicated by a 3rd person suffix such as $-w a$, as illustrated in (19b). ${ }^{24}$
a. kitohtsissino'toki
anna
si'kaan.
kit-oht-yissino'to-ok-i
anna
si'kaan
2-INST-catch.TA-INV-1
DEM
blanket.AN

'You caught me by using the blanket (e.g., not by using a rope).' (2>1)

b. *kit-oht-yissino'to-a-wa anna si'kaan

2-INST-catch.TA-DIR-3S

DEM

blanket.AN

Intended meaning: 'You used the blanket (not e.g., a rope), and caught someone.' $(2>3)$

(Cf. grammatical meaning: 'You caught someone using the blanket.' $(2>3))$

In (19b), the intended meaning is such that the direction of the action is from the 2nd person ('you') to the 3rd person animate instrument ('the blanket'); however, the sentence is ungrammatical with the intended meaning, suggesting that an instrument nominal introduced by a linker cannot be indexed via a theme marker. The grammatical meaning of this sentence where the direct object 'someone' is indexed by the theme marker is indicated for comparison. ${ }^{25}$

23 An object like 'the blanket' that belongs to the grammatically animate class in the language cannot be a beneficiary as it is not sentient, as shown in the previous section. However, as an animate nominal, it could be indexed by a theme marker if it were the object of a TA verb.

24 The suffix $-i$ in (19a) cannot appear in (19b). Otherwise, the verb in (19b) would be marked to agree with three participants, which is not an option allowed in the language.

25 As a reviewer points out, the proposed account in this section would be stronger if data with a linker where the direct object is inanimate and the nominal introduced by a linker is animate is presented, so that the data can be formed as a minimal pair to the applicative clause in (18). Such data has to be constructed with a TI verb, which takes an inanimate object and allows a direct theme marker only; for example, 'I ASSOC-saw.TI-DIR them with you.ASsoc.' If the associate nominal introduced by the linker were indexed by a direct theme marker $(1>2)$, this sentence would be ungrammatical in a similar way to the ungrammaticality of (19b). However, this example would be also ungrammatical due to the fact that the TI verb comes to have an animate object, i.e., the associate nominal 'you'. Thus, this type of example does not clearly separate the effects of theme markers and verb finals. 


\subsection{Suffixal agreement}

In Blackfoot, verbal suffixes on TA/TI verbs indicate the person and number of objects including beneficiaries, and those on $\mathrm{AI}$ verbs mark these features of the subject (see Section 2). For example, for ordinary TA and TI verbs where a direct object appears, the suffix - $w a$ indicates that the direct object is in 3rd person singular and the suffix $-y i$ indicates that the direct object is in 3rd person plural. In a ditransitive clause such as beneficiary clauses, the same forms of the suffixes indicate the number and person of the beneficiary, i.e., the primary object, not the theme nominal, a secondary object. Following Frantz (2009) and Ritter and Wiltschko (2014), I assume that this type of suffix is an agreement morpheme. Consider the beneficiary clause in (10a), repeated as (20) below. In this example, the verb 'sewed' shows suffixal agreement with the beneficiary 'the baby', as indicated by the 3rd person singular marker - wa. It does not agree with the secondary object, 'the blankets', which is plural, as the ungrammaticality of the third person plural agreement marker $-y i$ shows.

$$
\begin{aligned}
& \text { nitaahkanomoawa anna issitsimaan amiksi si'kaaniksi. } \\
& \text { nit-(w)aahkan-omo-a-wa/*-yianna issitsimaan am-iksi si'kaan-iksi } \\
& \text { 1-sew-BEN.TA-DIR-3S/-*3PL DEM baby DEM-AN.PL blanket-AN.PL } \\
& \text { 'I sewed those blankets for the baby.' }
\end{aligned}
$$

Nominals introduced by linkers, however, do not show suffixal agreement with the verb, as illustrated below with the instrument linker (21). In (21), the plural nominal 'sticks' is introduced by the instrument linker oht-, while the theme nominal of the verb 'hit' is singular 'John'. The verb shows agreement with the theme, as indicated by the 3rd person singular suffix - $w a$. If the verb agrees with the instrument, with the 3rd person plural marker $-y i$, the sentence is ungrammatical, as indicated in (21). The ungrammaticality of the suffixal agreement shown in (21) suggests that an oblique nominal introduced by a linker cannot be a primary object.

$\begin{array}{lllll}\text { nitohtaawaayakiawa anna John miistsisistsi. } & & \\ \text { nit-oht-waawayaki-a-wa/- } * y i & \text { anna } & \text { John } & \text { anni-istsi } & \text { miistis-istsi } \\ \text { 1-INST-hit.TA-DIR-3S/-3PL } & \text { DEM } & \text { John } & \text { DEM-PL } & \text { stick-INA.PL } \\ \text { 'I hit John with those sticks.' } & & & & \end{array}$

The data provided in this section demonstrates that oblique nominals introduced by linker prefixes cannot be primary objects, unlike those introduced by the benefactive suffix $-o(\mathrm{mo})$. The results of this section also suggest that oblique nominals introduced by a linker $\mathrm{P}$ cannot be analyzed in terms of Appl, unlike beneficiary nominals in the language or the applied objects in the previous literature (see Section 3). The differences between the nominals introduced by the 
Table 2: Differences between oblique nominals of linkers and of the beneficiary morpheme.

Oblique nominal

Blackfoot-specific properties of primary objects

\begin{tabular}{|c|c|c|}
\hline (i) Affix type of argument introducers: suffix & Prefix (linker iiht-/iihp-) & Suffix (-omo) \\
\hline (ii) Sentience restriction: $\checkmark$ & $x$ & $\checkmark$ \\
\hline (iii) Person prefix marking: $\checkmark$ & $x$ & $\checkmark$ \\
\hline (iv) Theme (DIRECT/INVERSE) marking: $\checkmark$ & $x$ & $\checkmark$ \\
\hline (v) Suffixal agreement: $\checkmark$ & $x$ & $\checkmark$ \\
\hline (vii) Obligatoriness of the affix: $\checkmark$ & $x$ & $\checkmark$ \\
\hline (vi) Category of the $V$ after affixation: changed & No change & Changed (to TA) \\
\hline
\end{tabular}

linker and the benefactive morpheme discussed in this section are summarized in Table 2 with the addition of the differences between them noted in Section 3.

Building on the data presented in this section, I propose that linker PPs are adjuncts, as with the previous studies that identified oblique PPs in Bantu-type languages as adjuncts for similar reasons (see the discussion in Sections 1 and 3).

A remaining question is how to account for the fact that oblique nominals of linker Ps do not show primary object properties even though the linker appears as if it forms a complex verb, much like the complex verb formed with the applicative affix. Addressing this question is the topic of the next section.

\section{Linkers, phases, and agree ${ }^{26}$}

\subsection{Late merge of linker PP at the phase level}

In addressing the question raised at the end of Section 4, I propose a late merge analysis of linker PPs, taking the view that adjuncts are integrated into a given derivation late, unlike non-adjuncts such as objects, as with Lebeaux (1988) and Stepanov (2001). In particular, I adopt Stepanov's (2001) proposal for the late merge of adjuncts laid out in the framework of Chomsky $(1995,2000)$, in which the derivation proceeds by Merge via feature checking. Assuming two types of Merge, namely adjunction and non-adjunction Merge, within Chomsky's system, it is proposed that a choice between these two Merges depends on the featural makeup of the

26 In making my claims in this section, at various points, I assume certain parts of the phrase structure proposed for Blackfoot in Ritter and Wiltschko (2014). However, I do not assume their particular proposal for the Parametric Substantiation Hypothesis (PSH). The proposed account made for the linkers in this paper does not hinge on the PSH. 
syntactic object that is undergoing Merge. ${ }^{27}$ A syntactic object labeled $\alpha$ merges with another syntactic object $\beta$ via adjunction only when $\alpha$ has no uninterpretable features to be checked. More specifically, lacking uninterpretable features, it cannot participate in the derivation cyclically but merges late after the cyclic derivation has completed. On the other hand, $\alpha$ merges with $\beta$ via non-adjunction Merge only when $\alpha$ has uninterpretable features to be checked. Being a non-adjunct, in this case, $\alpha$ undergoes cyclic derivation checking its uninterpretable features. ${ }^{28}$

In Section 4, linker PPs were demonstrated to be adjuncts lacking a range of properties of primary objects, unlike applied objects in the language. I propose that the lack of object properties reflects the lack of relevant uninterpretable features on linker PPs, as assumed in minimalist syntax (see also Footnote 28). Lacking the relevant features, linker PPs merge late via adjunction. Casting Stepanov's (2001) proposal into an Agree-based model (Chomsky 2000, 2001), I further propose that linker PPs, lacking relevant uninterpretable features, cannot participate in the derivation via Agree, but instead merge late. ${ }^{29}$ Assuming strongly cyclic syntax where the derivation proceeds by phases (Chomsky 2008), I propose that the specific point of the derivation where adjuncts such as linker PPs late merge is the end of a given phasal derivation (see Nissenbaum 2000 for a similar proposal for adjunct clauses generally). As for linker PPs, being modifiers of the event denoted by the verb phrase, they merge late at the end of (both agentive and non-agentive) $v \mathrm{P}$ derivations (e.g., see (25c)), assuming that (both types of) $v \mathrm{P}$ are phasal (Chomsky 2000; Marantz 2001; Legate 2003). ${ }^{30}$

27 In Stepanov (2001), “substitution Merge” (Chomsky 1995) is used, but I use "non-adjunction Merge" in this paper.

28 In Stepanov (2001), no discussion is provided as to how to determine whether a given syntactic object has uninterpretable features or not. Couching his proposal in minimalism (Chomsky 1995, 2000), adjuncts are assumed to have no uninterpretable features, while non-adjuncts (i.e., arguments with a grammatical function such as object) have uninterpretable features to be checked. As mentioned in the text, I also follow this position, assuming the featural distinction between adjuncts and non-adjuncts.

29 The idea that argument relations are driven by feature checking is similar to Hornstein (1999). Applied objects in Bantu and those in Blackfoot, by having uninterpretable features (as suggested in the previous literature e.g., McGinnis 2001), will participate in derivation cyclically via Agree valuing and checking matching features, which I do not further question.

30 The account proposed in this section departs from Stepanov (2001) in this respect. In Stepanov (2001), adjunction takes place "post-cyclically", i.e., at the end of the whole cyclic derivation. If this were the case, adjunct PPs in Blackfoot should merge with $v \mathrm{P}$ after the derivation up to CP is done, e.g., after the movement of [V-v] to INFL has already taken place. This makes the incorrect prediction of no linearization of $\mathrm{P}$ to the $[\mathrm{V}-\mathrm{v}]$ complex contrary to fact, and thus the affixal status of the linker $P$ remains unaccounted for. 
Now I turn to illustrating the proposed account using data with linker Ps. Consider the data in (22), where the instrument linker oht-introduces the DP 'those arrows'. Unlike non-adjuncts (e.g., objects) that participate in the syntactic derivation cyclically, the linker PP is built up separately ("on a different plane" (Chomsky 2001)), as in (23a), from the cyclic derivation of the rest of the verbal complex, $v \mathrm{P}$ (23b). The head of $v \mathrm{P}$ is the locus of the final suffix (e.g., TA) (see Section 3). Thus, the derivation of the linker PP (23a) is separated from the cyclic portion of the derivation of $v \mathrm{P}(23 \mathrm{~b})$. Within $v \mathrm{P}(23 \mathrm{~b})$, the verb stem $\mathrm{V}$ remerges to $v$ resulting in the order of $\mathrm{V}$ $v$, similar to the familiar verb movement to $v$ in English (see Section 5.2 for detailed discussion), which is also consistent with other studies on Blackfoot (e.g., Ritter and Rosen 2010).

(22) nitohtsissino'toawa anna saahkomaapi annistsi apssiistsi

nit-oht-yissino'to-a-wa ann-istsi apssi-istsi

1-INST-catch.TA-DIR-3s DEM-PL arrow.INA-PL

anna saahkomaapi

DEM boy.AN

'I caught that boy by means of those arrows.'

(23)
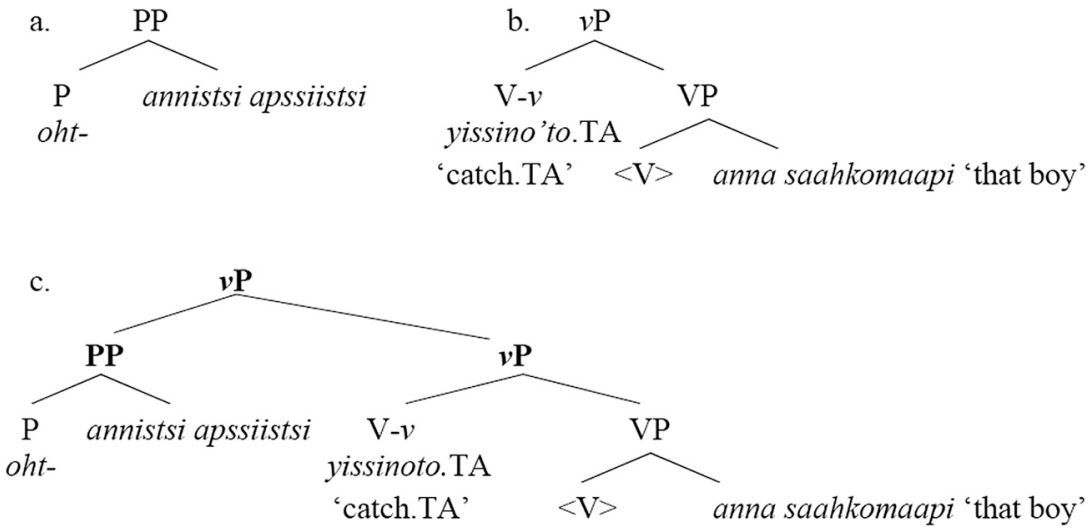

$v \mathrm{P}$ being phasal, the adjunct $\mathrm{PP}(23 \mathrm{a})$ merges with $v \mathrm{P}$ via adjunction, as shown in (23c), once $v \mathrm{P}$ is built up as in (23b). Assuming that the linearization is established phase-by-phase when spell out applies (Fox and Petsetsky 2005; Matushansky 2006; Nunes and Uriagereka 2000; Uriagereka 1999), in (23c), spell out applies at phasal $v \mathrm{P}$ which results in the linearization of the linker $\mathrm{P}$ with the relevant 
elements. As with Julien (2002), I propose that linker Ps linearize in their base position with the verb complex $[\mathrm{V}-\mathrm{v}]$, resulting in their surface appearance as prefixes, as in a [P-V-v] complex, oht-yissino'to.TA. ${ }^{31}$ Through an investigation into affix orders in genetically unrelated languages, Julien (2002) has shown that prefixes may not be the result of the traditional version of incorporation via head movement (Baker 1985, 1988), but result from linearization in their base position with other relevant syntactic materials. ${ }^{32}$ Taking the view of Julien (2002), I propose that linker Ps, on the surface, look as if they are incorporated into the complex [V-v] to which they are adjacent. Under this view, linkers do not undergo head movement that results in incorporation, unlike applicative affixes which undergo incorporation via head movement (see Sections 1 and 3). Consequently, a linker does not form a complex verb with $[\mathrm{V}-\mathrm{v}]$ and the lack of primary object properties shown by linker PPs is not an unexpected outcome.

In conclusion, oblique nominals introduced by linker Ps are unlike applied nominals in that the introducer, a linker, does not undergo incorporation via head movement. They also differ from oblique adjunct PPs in other languages in that the linker has the surface appearance of an affix to the verb. The proposed late merge analysis captures these properties of linker PPs, which were left unaccounted for in the previous analysis of incorporation via head movement or the adjunct analysis discussed in Section 3.

\subsection{The position of a linker $P$}

In the previous section, a linker $\mathrm{P}$ initially merges with its complement, and it is proposed that in the course of the derivation the linker $\mathrm{P}$ linearizes with the [V- $v]$ complex. However, it remains unclear how it comes to appear as a prefix on the verb, separated from its complement nominal. The affixal status of the linker P is important with respect to the main question raised by this paper (e.g., Sections 1 and 4): linkers in Blackfoot are verbal affixes similar to applicative affixes in other well-known languages, but the oblique nominals unexpectedly turn out to be adjuncts, which are

31 As mentioned in Section 2, the position of the nominal introduced by the linker and the object are fairly free; the object can precede the nominal introduced by the linker. That a derivation proceeds by phase does not suggest that the surface position of relevant syntactic elements should be fixed; as suggested by Matushansky (2006), for example, spell out fixes the internal structure, but not surface positions, e.g., $v \mathrm{P}$ fronting can take place after spell-out.

32 It is uncertain whether this kind of linearization can be generalized to all prefixes which introduce oblique nominals. For example, in Baker (1996), a prefixal applicative morpheme in Gunwinjguan languages introduces an oblique nominal that shows certain object properties, and is analyzed as undergoing incorporation forming a complex verb. I leave this issue for further research. 
usually introduced by independent Ps across languages. Thus, the current proposal should account for how linkers appear as verbal affixes, not as independent Ps.

I propose that the observed surface position of linker $\mathrm{P}$ on the verb, displaced from its initial merging position, can be accounted for by further remerge of [P-V-v] to higher heads, INFL and O(uter)-Asp, projected in the extended projections of verbs in the language. As will be discussed shortly in this section, I further propose that this remerge is motivated by Agree relationships between $\mathrm{V}$ and other higher functional heads in the extended verbal projection.

(24) nitohtsissino'toawa anna saahkomaapi anniistsi apssiistsi.

nit-oht-yissino'to- $a$ - $\emptyset$-wa anna saahkomaapi ann-istsi apssi-istsi

1-INST-catch.TA-DIR-ORDER-3S DEM boy.AN DEM-PL arrow.INA-PL

'I caught the boy by means of those arrows.'

Before discussing the proposed account, I introduce an assumption about the extended verbal projection for Blackfoot (e.g., Bliss et al. 2014; Ritter 2014), as illustrated in (25), where irrelevant details are omitted. Recall that $v$ is the locus of the final suffix (see Section 2); above $v \mathrm{P}$ is $\mathrm{O}-\mathrm{AspP}$, which is the locus of theme markers (Bliss et al. 2014) - a DIRECT or INVERSE suffix as discussed in Section 4.2. ${ }^{33}$ Above O-AspP is INFLP instantiated by an order suffix, $-h p$ or a zero morpheme (Ritter and Wiltschko 2014). ${ }^{34}$ In (24), a null order morpheme appears between the DIRECT theme marker $-a$ and the 3s suffix $-w a$, which has not previously been indicated in this paper. I only indicate it in this example and relevant examples in this section for convenience. Also, note that person prefixes such as nit- appear in the specifier of IP following Ritter and Wiltschko (2014), which will play a role in accounting for the morpheme order between linkers and the [V- $v$ ] complex discussed later in the section. ${ }^{35}$ This is sufficient detail to understand the remerge of $[\mathrm{V}-v]$ to $\mathrm{O}-\mathrm{AspP}$ and INFL, and I do not discuss in detail how INFL and $\mathrm{O}$-AspP are the loci of the relevant morphemes in the language, as these details are not relevant to the current discussion (see Footnotes 33 and 34 for a brief discussion).

33 Abstracting away from the details, O-Asp in Blackfoot corresponds to the same category that instantiates viewpoint aspect (cf. Smith 1991) in languages like English (Bliss et al. 2014).

34 Order suffixes indicate a distinction between local (1st and 2nd person) and non-local person (3rd person) involved in a given event, which is signaled by the form of the order suffix, either - $h p$ or a zero morpheme (Ritter and Wiltschko 2014). For further details, see Ritter and Wiltschko (2014).

35 Verbal suffixes that mark person and number agreement discussed in Section 4.4 are proposed to be realized in the CP domain (Bliss 2013), which I do not question. 


$$
\text { [IP person prefix INFL [o-ASP } \text { O-Asp } \quad\left[{ }_{v \mathrm{P}} v \quad[\mathrm{VP} \mathrm{V}]\right]
$$

Order suffix theme marker final suffix

Now I turn to the proposal of remerge of $\mathrm{V}$ into the higher functional heads, $v$, O-Asp, and INFL. Within minimalist syntax (e.g., Chomsky 1995, Chomsky 2001), although details differ, classical incorporation phenomena (in the sense of Baker 1985) have been viewed as involving feature checking (e.g., Julien 2002; Pesetsky and Torrego 2001; Matushansky 2006; Roberts 2010). For example, as schematically presented in (26), the uninterpretable feature of a probe $\mathrm{X}$ is checked by a goal $\mathrm{Y}$ with the matching interpretable feature in its c-command domain. As a consequence of the feature checking, the remerge of goal $\mathrm{Y}$ to $\mathrm{X}$ takes place.

$$
\mathrm{Y}[\mathrm{iF}]-\mathrm{X}[\mathrm{HF}] \quad \ldots<\mathrm{Y}[i \mathrm{~F}]>
$$

Likewise, I propose that the remerge of $\mathrm{V}$ in Blackfoot into higher heads is driven by an Agree relation between $V$ and the higher functional heads $v$, O-Asp, and INFL. In particular, I propose that the remerge of $\mathrm{V}$ to the higher functional heads checks an uninterpretable c(ategorial)-feature, as shown in many studies such as Julien (2002) and Matushansky (2006). Like these studies, I assume that c-features can appear on both functional and lexical heads. A head can c-select the syntactic category of its complement, and the relevant c-feature of the selecting head is the uninterpretable counterpart to the c-feature of its complement, e.g., $[u \mathrm{~V}]$ for $v$ that c-selects VP. Moreover, the c-selected head of the complement has an interpretable matching c-feature, e.g., [iV] for V. Importantly, in a case where more than one functional head appears in the extended projection, the lexical head of the projection determines the c-features of those functional heads (Julien 2002). What this means for Blackfoot $\mathrm{V}$ and its extended projection is that the functional heads, $v$, O-Asp, and INFL, all share a $[u \mathrm{~V}]$ feature, and the remerge of $\mathrm{V}$ takes place all the way upward, as illustrated in (27). Put differently, in (27), the probes $v$ (27a), O-Asp (27b), and INFL (27c) establish Agree relations with $V$ at each derivational stage: the $[u \mathrm{~V}]$ feature on these probes are checked by an $[i \mathrm{~V}]$ feature and thus the remerge of V into $v$ (27a), O-AspP (27b), and INFL (27c) sequentially takes place.
a. $\quad \ldots{ }_{\nu \mathrm{P}}\left[{ }_{\mathrm{PP}} \mathrm{P}\right.$
DP]
$\left.\left.\left[{ }_{\nu \mathrm{P}}[\mathrm{V}[i \mathrm{~V}]-v[\mathrm{HV}]][\mathrm{vp}<\mathrm{V}>]\right]\right]\right]$ oht ann-istsi apssi-istsi yissino'to.TA linker.INST 'those arrows'
b. $\quad \ldots$ [o-Asp $<[\mathrm{P}-\mathrm{V}[\mathrm{iV}]-v]>-\mathrm{O}-\mathrm{A}$ -
$\quad[$ oht-yissino'to.TA $]-a$ [oht-yissino'to.TA]- $a \quad<$ oht-> ann-istsi apssi-istsi
c. $\quad[$ IP $\quad$ person prefix $[\mathrm{P}-\mathrm{V}[\mathrm{iV}]-\mathrm{v}-\mathrm{O}-\mathrm{Asp}]-\mathrm{INFL}[\mathrm{HV}]$ [O-Asp $\left.\left.\ldots\left[{ }_{\nu \mathrm{P}} \ldots\right]\right]\right]$ [oht-yissino’to.TA-a]- $\varnothing$ $<$ oht-yissino'to-TA- $a>$ 
In (27a), linearization of the linker $\mathrm{P}$ and the $[\mathrm{V}-\mathrm{v}]$ complex takes place, resulting in $[\mathrm{P}-\mathrm{V}-\mathrm{v}]$, as discussed in the previous section. Subsequently to the linearization, $[\mathrm{V}-\mathrm{v}]$ remerges to $\mathrm{O}-\mathrm{AspP}$ along with $\mathrm{P}$, as in (27b). Here, curly brackets around the linker $\mathrm{P}$ are employed in order to indicate that its displacement is not a usual remerge resulting from feature checking. In the next step of the derivation in (27c), [P-V- $v$-O-Asp] remerges to INFL. I propose that the remerge to O-AspP shown in (27b) yields the stranding of the complement of the linker. Thus, the surface position of the linker appears to be a by-product of an Agree relation between a higher functional head (i.e., o-Asp) and the $[\mathrm{V}-v]$ complex to which the linker PP merged.

The current paper proposes that linker PPs merge at $v \mathrm{P}$, a projection lower than IP. Upon spell out, the linker P linearizes with a [V-v] complex and at the next step of the derivation, the $[\mathrm{P}-\mathrm{V}-\mathrm{v}]$ sequence remerges to INFL (27c) via 0 -AspP (27b). The prediction of this proposal is that a person prefix that merges in the specifier of IP (see (25/27c)) (e.g., Déchaine and Wiltschko 2014; Ritter and Wiltschko 2014 among others), if present, will always precede the linker, assuming that the person prefix is also the result of spell out in its base position (Julien 2002) (see Section 5.1). This prediction is borne out by the data, as shown in (24): the 1st person prefix nit- appears before the sequence of $[\mathrm{P}-\mathrm{V}-\mathrm{v}]$. As linker Ps move to the higher INFL through O-Asp as a part of [P-V-v], linker Ps will always appear after a person prefix, which appears in the specifier of IP (Ritter and Wiltschko 2014), as in (24) (see also (27c)). Moreover, the proposed account rules out the incorrect order in (28) where a linker (iiht-) precedes a person prefix (nit-). In other words, if the linker PP were an adjunct to a higher phrase than $v \mathrm{P}$, e.g., an IP, (28) would be a correct order, contrary to fact. ${ }^{36}$

\section{*iiht-nit-yission'to-a- $\emptyset$-wa}

In the sections to follow, I rule out the possibility of linker PPs merging lower than $v \mathrm{P}$. For example, the morpheme orders observed in (24) could be claimed to result from the linker PP merging between $v$ P and VP; I demonstrate using evidence from abstract nominalization and the distribution of idioms in Blackfoot that linker PPs cannot be added to a lower phrase than $v \mathrm{P}$, such as I(nner)-Asp between $v \mathrm{P}$ and VP. This further supports the account proposed in this section.

36 As for the locative linker it-, it is proposed to be an IP adjunction (Bliss et al. 2020), differently from the linkers discussed in this paper. As for the direction linker itap-, the nominal is proposed to be the object of a complex verb consisting of a motion verb and the direction linker, not an adjunct (Kim 2017b), unlike the proposal in this paper. It appears that not all linkers are adjuncts, or adjoin to the same type of phrase. More evidence for the $v \mathrm{P}$ adjunction analysis is discussed in Section 6. 


\section{Linkers and lower phrases than $v \mathrm{P}$}

Here I present two distinct pieces of empirical evidence (abstract nominalization and the distribution of idioms) which together suggest that linker PPs appear at $v \mathrm{P}$ as proposed in this paper. Specifically, the data from abstract nominalization and the data from idioms independently show that linker PPs appear above I-AspP, which sits between $v \mathrm{P}$ and VP in Blackfoot. Thus, these data lend further support to the current analysis in which the adjunction site of linkers is $v \mathrm{P}$. Moreover, the data of these linkers is contrasted with another set of prefixes, i.e., non-linkers (Frantz 2009; Frantz and Russell 1995), which indicates adpositional meaning in the language, briefly discussed below. The comparison indicates that non-linkers appear below I-AspP.

Non-linkers indicate adpositional meanings such as direction or location, similar to particles in other familiar languages, and I assume that they belong to the category P as with previous studies (e.g., Kim 2014, 2015a). As the name suggests, in contrast to linkers, they cannot introduce a nominal, as illustrated in (29). In (29), the directional non-linker waamis 'up' is present and indicates a direction for the motion 'jump'. Unlike linkers, it cannot introduce a nominal, e.g., 'that hill'.

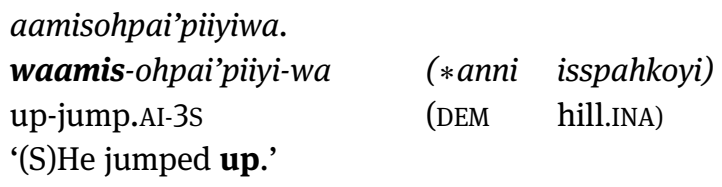

'(S)He jumped up.'

In what follows, I show that linkers are different from non-linkers in their position, appearing higher above I-Asp, a projection below $v \mathrm{P}$, despite having similar adpositional meanings to those of non-linkers.

\subsection{Abstract nominalization}

Abstract nominalization in Blackfoot shows that linker PPs must appear above I-AspP. Abstract nominalization in Blackfoot is one of the several nominalization types available in the language, and it targets intransitives only, such as AI verbs (Bliss et al. 2012; Frantz 2009). ${ }^{37}$ Abstract nominalization is morphologically marked with $-n$ or $-h \sin$ : the first variant attaches to stems ending in $-a a$, and the second allomorph appears elsewhere. Abstract nominalization indicates either the

37 Thus, a beneficiary applicative clause marked as a TA verb is ungrammatical with abstract nominalization. 
state or process described by the verb (Frantz 2009). An example of abstract nominalization is illustrated in (30). ${ }^{38}$

$$
\begin{aligned}
& \text { o'kaani } \\
& \text { o'kaa-n-yi } \\
& \text { sleep-NOM-s } \\
& \text { 'sleep' }
\end{aligned}
$$

(Frantz 2009:115)

In a recent study of abstract nominalization in this language (Ritter 2014), it is shown that the source of the nominalization is I-Asp (in the sense of Travis 2010), located between $v \mathrm{P}$ and $\mathrm{VP}$, as represented in (31).

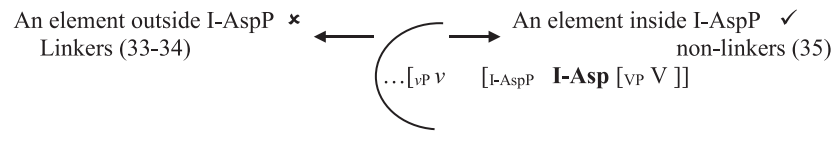

Abstract nominalization will be contrasted with another type of nominalization in the language, namely conjunct nominalization (glossed as $\mathrm{CN}$ ), which is illustrated in (32) (Frantz 2009). Unlike abstract nominalization, conjunct nominalization is proposed to target IP (Bliss 2014), which contains a $v \mathrm{P}$, which this paper also assumes.

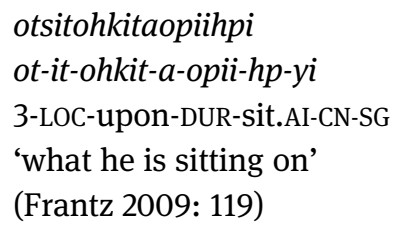

The proposal that abstract nominalization targets I-Asp (31) predicts that elements outside I-Asp cannot undergo abstract nominalization, while elements inside I-Asp can. In particular, regarding the linkers, it would be predicted that they should not undergo abstract nominalization if they appear outside I-Asp. In contrast, under the proposed analysis of this paper, the linkers are predicted to be grammatically able to undergo conjunct nominalization, as they are adjoined to $v \mathrm{P}$ contained within IP.

The predictions are borne out by the data. First, with respect to abstract nominalization, linker PPs, and just linker Ps, are ungrammatical with abstract

38 In (30), I do not mark a distinction in animacy for the singular suffixes for the sake of consistency in this paper. 
nominalization, as shown in (33-34), which are nominalizations of (12) and (6b), respectively. Note that this is the case regardless of whether an oblique nominal is absent or present. ${ }^{39}$

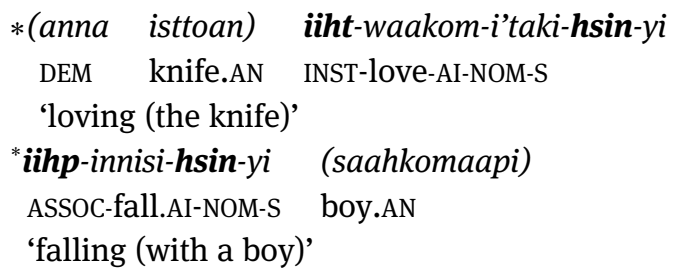

This ungrammaticality suggests that linker PPs attach to a phrase higher than I-AspP, supporting the proposed analysis of linker PPs as a $v$ P adjunction. Nonlinker PPs contrast with linkers in this respect. They are grammatical with abstract nominalization, as shown in (35) with the non-linker waamis 'up'. This grammaticality suggests that non-linker PPs attach to a phrase below I-Asp, unlike linker PPs.

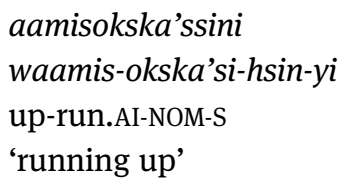

With respect to conjunct nominalization, linkers are grammatical, as shown in (36). The grammaticality of linkers in conjunct nominalization follows from the proposed analysis in this paper: as a linker PP adjoins to $v \mathrm{P}$, it is contained within IP; therefore, nominalizing the IP that contains the linker PP yields a grammatical result, as shown in (36). ${ }^{40}$

\author{
iihtaohpommao'pa \\ iiht-a-ohpommaa-o'p-wa \\ INST-DUR-buy.AI-21:CN-3s \\ 'money/what one buys with'
}

(Frantz 2009:120)

39 The fact that unaccusative AI verbs are ungrammatical with abstract nominalization as shown in (34) may suggest that an unaccusative $v$ P merges above I-AspP. Although interesting, I do not question these issues, which are beyond the scope of this paper.

40 A beneficiary applicative clause analyzed as ApplP in the language (see Section 3) is thus predicted to undergo conjunct nominalization, which is the case (Frantz 2009). The fact that both linker PPs and ApplPs show the same pattern with respect to conjunct nominalization does not affect the proposal made in this paper in which linker PPs are adjuncts. What the fact regarding the nominalization shows is that the height of the linker PP and ApplP in the clause structure is similar, both being higher than I-AspP. 
To summarize, evidence from abstract nominalization indicates that linker PPs appear above I-AspP (which is lower than $v \mathrm{P}$ ), in contrast with non-linker PPs, which appear below I-Asp; this is represented in (37). Together with the evidence that linker PPs cannot be IP-adjuncts as discussed in Section 4, the conclusion illustrated in (37) provides further support for the analysis proposed in this paper that a linker PP merges at $v \mathrm{P}$, which appears higher than I-AspP (as an adjunct).

$$
\left[{ }_{v \mathrm{P}} \ldots\right. \text { linker PP... [I-AspP ... non-linker PP... ]] }
$$

Furthermore, the positions of linker and non-linker PPs as proposed in (37) predict that they can co-occur. This is borne out as illustrated in (38). In (38), the non-linker waamis- 'up' appears with the instrument linker oht- and the sentence is grammatical. $^{41}$

(38) nitohtaamisokska'si anni naapioyisi.

nit-[oht-waamis-okska'si] anni naapioyisi

I-[INST-up-run.AI] DEM house.INA

'I ran up, because of this house.'

[In a context where the house is a haunted house, and I got scared of this house.]

\subsection{Idioms}

In this section, building on evidence from idioms, I show that non-linker PPs appear VP-internally, while linker PPs appear above I-Asp, consistent with the conclusion drawn from abstract nominalization. This is represented in (39).

$$
\left[{ }_{\nu \mathrm{P}} \quad \ldots \text { linker PP ... [ }{ }_{\nu \mathrm{P}} v\right. \text { [I-AspP I-Asp [vP V non-linker PP ] ]]] }
$$

A generalization drawn from studies on idioms in the verbal domain is that material outside VP does not generally form part of an idiom with the verb, while material inside VP commonly tends to do so (e.g., Laron 1988; Marantz 1997). For example, Marantz (1997) proposes that agents outside VP (introduced by $v /$ Voice) usually do not take part in idiom formation, while objects inside VP easily form idioms with the verb. Furthermore, recent approaches to idioms (e.g., Harwood 2015; Kim 2015b; Svenonius 2005) suggest that this is not merely a distinction between agents and objects, but that the distinction can map onto a phasal

41 Non-linkers such as in (35) are optional to the argument structure of the verb (Kim 2015a). Assuming a version of strongly cyclic derivation where every node is a phase (e.g., Marantz 2001), non-linker PPs would be added at VP, and they linearize with V in a similar fashion to the way linker Ps linearize. 
boundary. For example, a phase head such as $v$ can be a boundary for idiom formation; material inside $v$ can participate in idiom formation, while material outside $v$ does not usually participate in idiom formation. ${ }^{42}$

To illustrate, I discuss Slavic prefixes, which to some extent parallel Blackfoot's linkers and non-linkers. Slavic is known to have two types of prefixes: lexical and superlexical. These largely belong to the class of prepositional elements (see Svenonius 2004, 2005 and references therein). Examples of lexical and superlexical prefixes are illustrated with $z a$ - in Russian in (40). It is used as a lexical prefix meaning 'into' in (40a), and as a superlexical prefix in (40b). Under this latter usage, the prefix has the aspectual meaning 'begin to'; thus, the verbal complex has the meaning 'starting to throw'.

a. Helder za-brosil mjač $v$ vorota angličan
Helder into-threw ball in goal English
'Helder kicked the ball into the English goal.'
b. Ricardo nervno za-brosal mjač.
Ricardo nervously INCP-threw ball
'Ricardo began to nervously throw the ball.'
Svenonius 2004:205)

Putting aside other properties of lexical prefixes (see Svenonius 2004 for details), these prefixes easily form idiomatic expressions, as illustrated with a Russian example in (41).

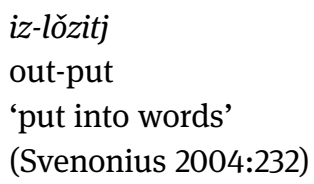

On the other hand, it is rare that superlexical prefixes form idiomatic expressions (Svenonius 2004). The typical meanings of superlexical prefixes are transparent, as shown in (42).

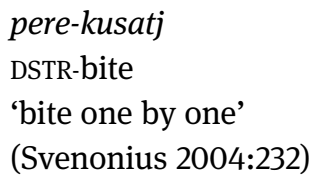

42 The relevant boundary is proposed to be a phase such as $v \mathrm{P}$ (Svenonius 2005) or ApplP (Kim 2015b). Moreover, Harwood (2015) proposes that within clauses the phase boundary can be flexible, either being $v \mathrm{P}$ or the Progressive aspect phrase. 
Building on the idiomatic patterns of these prefixes (and other properties; see Svenonius 2005 for details), Svenonius proposes that lexical prefixes merge below the phase head, $v$ (e.g., in VP), while superlexical prefixes are realized above the phase head $v$ (e.g., in AspP). Thus, the pattern of idioms involving prefixes in Russian supports the view that a phasal head such as $v$ can be a boundary for idiom formation.

If the phasal boundary for idioms in Blackfoot is also a $v$ head, to whose projection linker PPs adjoin (see Section 5), the positions of linker PPs (above $v$ ) and non-linker PPs (below $v$ ), as proposed in (39), predict that linker PPs may not belong to idioms, being outside the boundary for idiom formation, i.e., $v$, and, conversely, that non-linker PPs may form idioms with the verb, being inside the boundary. This type of split in idiom formation patterns is exactly what is found with linkers and non-linkers; in Blackfoot it is easy to find idioms formed with nonlinkers but this is not the case with the linkers. The Blackfoot dictionary (Frantz and Russell 1995) shows numerous idioms that consist of a non-linker and a verb, some of which are illustrated in (43). Strikingly, in the dictionary, there are no idioms formed with linkers. ${ }^{43}$

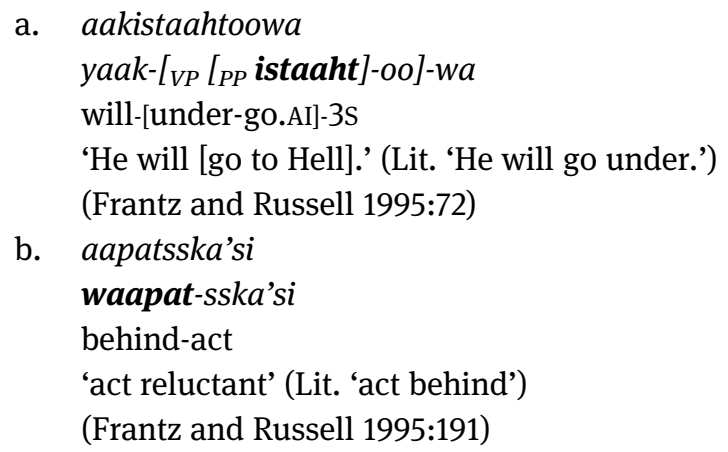

a. aakistaahtoowa yaak-[VP [PP istaaht]-oo]-wa

will-[under-go.AI]-3S

'He will [go to Hell].' (Lit. 'He will go under.')

(Frantz and Russell 1995:72)

b. aapatsska'si

waapat-sska'si

behind-act

'act reluctant' (Lit. 'act behind')

(Frantz and Russell 1995:191)

Building on the fact that non-linkers appear below I-AspP and that they can form idioms with the verb, I propose that non-linkers appear below $v$, inside the VP as in (39). The lack of idioms containing linkers supports the account proposed in this

\footnotetext{
43 It would be interesting to know if idiom formation is possible with a beneficiary applicative suffix. I could not find any in the dictionary or elicit one. The absence of idioms that contain an applicative suffix may be expected, given a recent proposal that an Appl head above VP constitutes a phasal boundary for idiom formation (e.g., Kim 2015b), consistent with the assumptions in this section.
} 
paper in which linker PPs adjoin to $v \mathrm{P}$ above the phase head $v$, the boundary for idiom formation. ${ }^{44}$

\section{Conclusion}

This article proposes an analysis for oblique nominals introduced by certain verbal affixes, namely linker Ps, in Blackfoot. Linker Ps are similar to applicative affixes in that they introduce an oblique nominal and appear as verbal affixes as if forming a complex verb. This article shows that these similarities are only surface phenomena. Unlike applicative affixes, it is shown that a linker P forms an adjunct with its oblique nominal. For the adjunct status of linker PPs, a late merge analysis is proposed: linker PPs, as adjuncts, merge late as they lack relevant features to participate in an Agree-based derivation. Moreover, it has been shown that the surface appearance of linker Ps is not the result of the usual incorporation via head movement proposed for applicative affixes (e.g., Baker 1985): it is not the result of a head movement to the verb, but is the consequence of the linker's linearizing with a verb complex $(\mathrm{V}-v)$ where the linker merges, i.e., $v \mathrm{P}$. Under this view, linker Ps do not form a complex verb with [V-v], consistent with the lack of object properties.

Linker-like morphemes in other Algonquian languages have been treated as unusual elements due to the distinct properties (e.g., lacking primary object properties) they display. The contribution of this paper to that issue is to provide empirical evidence that linkers in Blackfoot also appear to be unusual in a similar way (Section 4.1-4.4). The theoretical contribution of this paper has been to provide an analysis of the linkers in minimalist syntax (Section 5), which has been lacking in current (Algonquian) literature. Although linkers introduce oblique nominals, they do not pattern like applicative suffixes, another typical kind of oblique nominal-introducer in the language. The linkers also fail to pattern like other P-like elements such as non-linkers (Section 6). Current literature on the argument structure of oblique nominals centers on clear-cut cases like Bantu applicatives or similar cases that have been assumed to belong to the realm of applicatives. This paper contributes to clarifying these issues by analyzing the distinct syntactic properties of oblique nominals introduced by linkers in Blackfoot.

44 A reviewer raises the concern that the phrases in (43) may not be real idioms, which is not a straightforward question to resolve. As far as the speakers with whom I consulted are concerned, they accepted the idiomatic meanings of the phrases in (43). In this paper, I assume that these types of examples belong to the set of idioms in the language. 
Acknowledgments: I would like to thank Sandra Many Feathers (formerly Crazybull) and Brent Prairie Chicken for sharing their language with me, and Betsy Ritter for her helpful comments at various stages of this research. I wish to thank the audience at the 44th North East Linguistic Society in 2013 for their comments. The early version of this work appears in the Proceedings of the 44th Annual Meeting of the North East Linguistic Society. Of course, all errors are my own.

\section{References}

Adger, David \& Daniel Harbour. 2007. Syntax and syncretisms of the person case constraint. Syntax 10(1). 2-37.

Alsina, Alex \& Sam Mchombo. 1990. The syntax of applicative in Chichewa: Problems for a theta theoretic asymmetry. Natural Language and Linguistics Theory 8(4). 493-506.

Baker, Mark. 1985. Incorporation: A theory of grammatical function changing. Cambridge, MA: Massachusetts Institute of Technology dissertation.

Baker, Mark. 1988. Incorporation: A theory of grammatical function changing. Chicago, IL: University of Chicago Press.

Baker, Mark. 1996. The polysynthesis parameter. New York: Oxford University Press.

Baker, Mark. 2006. On zero agreement and polysynthesis. In Peter Ackema, Patrick Brandt, Maaike Schoorlemmer \& Fred Weeman (eds.), Arguments and agreement, 289-331. 0xford: Oxford University Press.

Baker, Mark \& Chris Collins. 2006. Linkers and the internal structure of vP. Natural Language and Linguistic Theory 24(2). 307-354.

Bliss, Heather. 2007. Object agreement in Blackfoot: Sentient and non-sentient controllers. In H. Christoph Wolfart (ed.), Papers of the 38th Algonquian conference, 11-28. Winnipeg: University of Manitoba Press.

Bliss, Heather. 2010. Argument structure, applicatives, and animacy in Blackfoot. InHeather Bliss \& Raphael Girard (eds.), WSCLA 13 \& 14: Proceedings of the 13 and 14th Workshop on the Structure and Constituency of Languages of the Americas, 58-69. Vancouver, BC: UBC Working Papers in Linguistics.

Bliss, Heather. 2013. The Blackfoot configurationality conspiracy: Parallels and differences in clausal and nominal structures. Vancouver, BC: University of British Columbia dissertation.

Bliss, Heather. 2014. Assigning reference in clausal nominalizations. In Paul Ileana (ed.), Cross linguistic investigations of nominalization patterns, 85-118. Amsterdam \& Philadelphia: John Benjamins.

Bliss, Heather, Elizabeth Ritter \& Martina Wiltschko. 2012. Blackfoot nominalization patterns. In Monica Macaulay \& Randolph Valentine (eds.), Papers of the 44th Algonquian Conference, 1-21. Albany, NY: SUNY Press.

Bliss, Heather, Elizabeth Ritter \& Martina Wiltschko. 2014. A comparative analysis of theme marking in Blackfoot and Nishnaabemwin. In Monica Macaulay \& Randolph Valentine (eds.), Paper of the 42nd Algonquian Conference, 10-33. Albany, NY: SUNY Press.

Bliss, Heather, Rose-Marie Déchaine \& Tomio Hirose. 2020. Mutation in Dx: Spatial PPs in Blackfoot and Plains Cree. In Silvia Rossi \& Jacopo Garzonio (eds.), Variation in P: Comparative approaches to adpositional phrases, 164-190. Oxford: Oxford University Press. 
Bloomfield, Leonard. 1946. Algonquian. In Harry Hoijer (ed.), Linguistic structures of native America, vol. 6, 85-129. New York: Viking Fund Publications in Anthropology.

Bresnan, Joan \& Lioba Moshi. 1993. Object asymmetries in comparative Bantu syntax. In Sam Mchombo (ed.), Theoretical aspects of Bantu grammar, 50-93. Stanford, CA: CSLI Publications.

Chomsky, Noam. 1995. The minimalist program. Cambridge, MA: The MIT Press.

Chomsky, Noam. 2000. Minimalist inquiries: The framework. In Roger Martin, David Michaels \& Juan Uriagereka (eds.), Step by step: Essays on minimalist syntax in honor of Howard Lasnik, 89-155. Cambridge, MA: The MIT Press.

Chomsky, Noam. 2001. Derivation by phase. In Michael Kenstowicz (ed.), Ken Hale: A life in language, 1-52. Cambridge: The MIT Press.

Chomsky, Noam. 2008. On Phases. In Robert Freidin, Carlos. P. Otero, \& Maria Luisa Zubizarreta (eds.), Foundational issues in Linguistics Theory, 133-166. Cambridge, MA: MIT Press.

Cuervo, Christina. 2003. Datives at large. Cambridge, MA: Massachusetts Institute of Technology dissertation.

Déchaine, Rose-Marie \& Martina Wiltschko. 2014. Micro-variation in agreement, clause-typing and finiteness: Comparative evidence from Plains Cree \& Blackfoot. In Randolph Valentine \& Monica Macaulay (eds.), Papers of the 42nd Algonquian Conference, 69-101. New York: SUNY Press.

den Dikken, Marcel. 2006. Relators and linkers: The syntax of predication, predicate inversion, and copulas. Cambridge: The MIT Press.

Fox, Danny \& David Pesetsky. 2005. Cyclic linearization of syntactic structure. Theoretical Linguistics 31. 1-45.

Frantz, Donald, \& Norma Russell. 1995. Blackfoot dictionary of stems, roots, and affixes. Toronto: University of Toronto Press.

Frantz, Donald. 2009. Blackfoot grammar. Toronto: University of Toronto Press.

Harwood, William. 2015. Being progressive is just a phase: Celebrating the uniqueness of progressive aspect under a phase-based analysis. Natural Language and Linguistic Theory 33(2). 523-573.

Hornstein, Norbert. 1999. Movement and control. Linguistic Inquiry 30(1). 69-96.

Julien, Marit. 2002. Syntactic head and word formation. Oxford: Oxford University Press.

Kim, Kyumin. 2012. Argument structure licensing and English have. Journal of Linguistics 48(1). 71-105.

Kim, Kyumin. 2014. Refining the syntax of non-core arguments: P, applicative, and functional p. In Jyoti lyer \& Leland Kusmer (eds.), Proceedings of the 44th North East Linguistic Society (NELS 44), 205-219. Amherst, MA: GLSA Publications.

Kim, Kyumin. 2015a. Spatial PPs and structure of motion verbs in Blackfoot. In Natali Weber \& Sihwei Chen (eds.), Proceedings of the 19th Workshop on Structure and Constituency in the Languages of the Americas (WSCLA 19), 125-139. Vancouver, BC: UBC Working Papers in Linguistics.

Kim, Kyumin. 2015b. Phase based account of idioms and its consequences. Linguistic Research 32(3). 631-670.

Kim, Kyumin. 2017a. Animacy and transitivity alternations in Blackfoot. In Monica Macaulay \& Margaret Noodin (eds.), The Papers of the 46th Algonquian Conference, 123-140. East Lansing, MI: Michigan State University Press.

Kim, Kyumin. 2017b. PP arguments, agree and incorporation. Studies in Generative Grammar 27(2). 309-326. 
Larson, Richard K. 1988. On the double object construction. Linguistic Inquiry 19(3). 335-391.

Lebeaux David. 1988. Language acquisition and the form of the grammar. Amherst, MA: University of Massachusetts dissertation.

Legate, Julie Anne. 2003. Some interface properties of the phase. Linguistic Inquiry 34(3). 506515.

Marantz, Alec. 1982. Affixation and the syntax of applied verb constructions. In Daniel P. Flickinger, Marlys Macken \& Nancy Wiegand (eds.), Proceedings of the first West Coast conference on linguistics, 330-340. Stanford, CA: Stanford University.

Marantz, Alec. 1984. On the nature of grammatical relations. Cambridge, MA: The MIT Press.

Marantz, Alec. 1993. Implications of asymmetries in double object constructions. In Sam Mchombo (ed.), Theoretical aspects of Bantu grammar 1, 113-150. Stanford, CA: CSLI Publications.

Marantz, Alec. 1997. No escape from syntax: Don't try morphological analysis in the privacy of your own lexicon. In Alexis Dimitriadis, Laura Siegel, Clarissa Surek-Clark \& Alexander Williams (eds.), Proceedings of the 21st Annual Penn Linguistics Colloquium, 201-225. Philadelphia, PA: University Pennsylvania Working Papers in Linguistics.

Marantz, Alec. 2001. Words. In Paper presented at West Coast Conference on Formal Linguistics (WCCFL) 20, Los Angeles: University of Southern California, 23-25 February.

Matushansky, Ora. 2006. Head movement in linguistic theory. Linguistic Inquiry 37(1). 69-109.

McGinnis, Martha. 2001. Variation in the phase structure of applicatives. Variations Yearbook 1. 101-142.

Meadows, Kim. 2010. The associative construction in Blackfoot. Calgary, AB: University of Calgary, MA thesis.

Nakamura, Masanori. 1997. Object extraction in Bantu applicatives: Some implications for minimalism. Linguistic Inquiry 28(2). 252-280.

Nissenbaum, Jon. 2000. Investigations of covert phrase movement. Cambridge, MA: Massachusetts Institute of Technology dissertation.

Nunes, Jairo \& Uriagereka, Juan. 2000. Cyclicity and extraction domains. Syntax 3. 20-43.

Pesetsky, David \& Torrego, Esther. 2001. T-to-C movement: Causes and consequences. In Michael Kenstowicz (ed.), Ken Hale: $A$ life in language, 355-426. Cambridge, Mass.: MIT Press.

Peterson, David A. 2007. Applicative constructions. Oxford: Oxford University Press.

Pylkkänen, Liina. 2008. Argument introducers. Cambridge, MA: The MIT Press.

Ritter, Elizabeth. 2014. Nominalizing inner-aspect: Evidence from Blackfoot. In Paul Ileana (ed.), Cross-linguistic investigations of nominalization patterns, 25-50. Amsterdam \& Philadelphia: John Benjamins.

Ritter, Elizabeth. 2015. Selection for [m] in Blackfoot: Consequences for Event structure. A paper presented at Séminaire de Recherche en Linguistique. Geneva, Switzerland.

Ritter, Elizabeth \& Sara Rosen. 2010. Animacy in Blackfoot: Implication for event structure and clause structure. In Malka Rappaport-Hovav, Edit Doron \& Ivy Sichel (eds.), Syntax, lexical semantics and event structure, 124-152. Oxford: Oxford University Press.

Ritter, Elizabeth \& Sara Rosen. 2005. Agreement without A-positions: Another look at Algonquian. Linguistic Inquiry 36(4). 648-660.

Ritter, Elizabeth \& Martina Wiltschko. 2014. The composition of INFL. An exploration of tense, tenseless languages, and tenseless constructions. Natural Language and Linguistic Theory 32(4). 1331-1386. 
Rhodes, Richard. 2010. Relative root complement: A unique grammatical relation in Algonquian syntax. In Jan Wohlgemuth \& Michael Cysouw (eds.), Rara \& rarissima: Documenting the fringes of linguistic diversity, 305-324. Berlin \& New York: De Gruyter Mouton.

Roberts, Ian. 2010. Agreement and head movement: Clitics, incorporation, and defective goals. Cambridge, MA: The MIT Press.

Smith, Carlota. 1991. The parameter of aspect. Dordrecht: Kluwer Academic Publishers.

Speas, Peggy \& Carol, Tenny. 2003. Configurational properties of point of view roles. In Aana Maria di Scuillo (ed.), Asymmetry in grammar, 315-344. Amsterdam \& Philadelphia: John Benjamins.

Stephanov, Arthur. 2001. Late adjunction and minimalist phrase structure. Syntax 4(2). 94-125. Svenonius, Peter. 2004. Slavic prefixes inside and outside VP. Nordlyd 32(2). 205-253.

Svenonius, Peter. 2005. Extending the extension condition to discontinuous idioms. Linguistic Variation Yearbook 5. 227-263.

Travis, Lisa. 2010. Inner aspect. Dordrecht: Springer.

Uriagereka, Juan. 1999. Multiple spell-out. In Samuel David Epstein \& Norbert Hornstein (eds.), Working minimalism, 251-282. Cambridge, MA: The MIT Press.

Wiltschko, Martina \& Ritter Elizabeth. 2015. Animating the narrow syntax. The Linguistic Review 32. 869-908. 